\author{
MAGDALENA ALEKSANDRZAK \\ Uniwersytet im. Adama Mickiewicza w Poznaniu
}

\title{
Problems and challenges in teaching and learning speaking at advanced level
}

\begin{abstract}
The article deals with the problems of teaching and learning speaking, in particular those which are most relevant in the context of developing oral skills at the advanced level of foreign language proficiency. The complex nature of spoken discourse must be taken into account and reflected at each stage of the learning process. Thus, the article examines the difficulties connected with choosing the appropriate framework and approach and discusses the typical patterns of interaction in the foreign language classroom. It also examines forms of control and evaluation and suggests some speaking activities which seem most suitable for advanced language learners in the light of the above theoretical considerations.
\end{abstract}

KEYWORDS: speaking skill, genre, task, interaction, testing, evaluation.

\section{GENERAL PROBLEMS IN TEACHING SPEAKING}

The position of speaking in the hierarchy of language skills has evolved over the centuries. Rather ignored in the Grammar - Translation Method, it became a primary skill in the Direct Method. Audiolingualism brought even more focus on speaking, although the linguistic principle it was based on viewed oral discourse as imitative routine behaviour in typical and predictable situations. The grammatical syllabus of the Cognitive Method incorporated activities in all language skills, attaching equal importance to each of them. Finally, Communicative Language Teaching added a more realistic dimension to teaching oral discourse by introducing numerous forms of interaction to the classroom and practising the language in natural or probable situations which demanded defining of the discourse genre and the roles of participants. Although the contribution of CLT to developing forms of speaking practice in the language classroom can hardly be overestimated, 
there is a growing tendency among researchers and practitioners to criticize it for its insufficient recognition of the complexity of speaking as a psycholinguistic process and of placing too strong an emphasis on information gap criterion as leading to artificial or impractical tasks (Dakowska 2005).

Nowadays, in spite of the inevitable criticism of available methods, techniques or resources, speaking is generally perceived as the most fundamental skill to acquire. Since the onset of the communicative era it has been treated as the ultimate goal of language training and its proper development has become the focus of attention of both teachers and learners. However, it is also a commonly recognized fact that achieving proficiency in foreign language speaking in classroom conditions is not an easy task. Even advanced learners often finish a language course with the conviction that they are not sufficiently prepared for speaking beyond the classroom. This difficulty results basically from the character and inadequate frequency of speaking opportunities in the classroom in comparison to the abundance of natural varieties and genres of oral communication. In fact, selecting the most appropriate types of spoken discourse for classroom practice in a particular language course is a very hard decision which, unfortunately, hardly ever reflects the natural occurrence and distribution of communicative situations.

Additionally, an advanced language course should create optimal conditions for developing learners' sociocultural knowledge, that is "the culturally embedded rules of social behaviour" (Thornbury 2007: 31) and their linguistic knowledge, which includes discourse and speech act knowledge, and knowledge of the grammar, vocabulary and phonology of the target language. These knowledge areas must then be appropriately activated in order to be made available for use in regular speaking practice in the classroom and beyond.

Importantly, as far as the stages of mental processing involved in speaking are concerned, there is not much difference between native and target languages. Both combine the processes of conceptualizing, formulating, articulating, self-monitoring and negotiating. Yet, the skill of speaking is not automatically transferable from the speaker's first language into the second (Thornbury 2007). Even extensive knowledge of the target language's grammar and vocabulary often presented by advanced students of foreign language departments does not guarantee success in oral communication when this knowledge is not properly integrated or accessed. Problems in speaking may be additionally aggravated by excessive use of self-monitoring processes and a tendency to formulate utterances in the native language first. These mental operations create obvious costs in terms of fluency and may lead to producing artificial discourse.

Other problems that are commonly observed in the language classroom are related to individual learners' personalities and attitudes to the learning 
process and learning speaking in particular. They can be defined as follows (Ur 1995: 121):

- inhibition - fear of making mistakes, losing face, criticism; shyness;

- nothing to say - learners have problems with finding motives to speak, formulating opinions or relevant comments;

- low or uneven participation - often caused by the tendency of some learners to dominate in the group;

- mother-tongue use - particularly common in less disciplined or less motivated classes, learners find it easier or more natural to express themselves in their native language.

As many teachers' observations indicate, the above situations occur in language classrooms regardless of the level of proficiency or the number of students in the group. Moreover, every learner enters any learning and communicative environment with his or her entire personality additionally shaped by their prior learning and communicative experiences, both positive and negative. This individual dimension is particularly noticeable among older and more advanced learners who often have a good insight into the nature of their individual difficulties, an accurate assessment of the skills they have already developed and, consequently, clearly defined needs.

\section{CHOOSING AN APPROACH}

Designing a speaking syllabus depends on several factors, the most obvious being the age and level of learners, the learning context and the aim of teaching. First, it must be defined how much emphasis can be given to speaking within a particular course and whether speaking is to be taught separately or integrated with the teaching of other skills and areas of the language. Secondly, it is essential to choose an approach which defines the teaching procedure. The selection between a task-based approach, a genrebased one or the combination of both types is the most crucial step in designing the course as it influences all the elements of the learning process in progress. Nevertheless, a modern multi-layered syllabus should specify the target aspects of the speaking skill to be taught, as well as the grammar and vocabulary components (Thornbury 2007).

A genre-based approach focuses on the notion of the communicative situation which centres around a particular spoken genre or genres. Needless to say, the variety of types of communicative situations is virtually unlimited. As a consequence, the teacher faces the necessity of deciding which situations should be included in the language course he or she coordinates. This selection, however well-thought-out it may be, is always connected 
with eliminating or ignoring a number of relatively significant situations and concentrating on those which seem most relevant to the particular learning context. The next step is defining the most important parameters of the selected situations, such as the topics, goals, discourse genres, social and cultural norms. The actual teaching procedure starts from establishing the social purpose and cultural context of a given genre, later a typical example is presented and analyzed, finally learners create their own samples of appropriate communicative events (Thornbury 2007: 121).

In contrast, a task-based approach stems from the general idea that "a language is best learned through using it, rather than learned and then used" (Thornbury 2007: 119). Consequently, it is believed that accuracy results from fluency, in other words the need to communicate effectively leads to the refinement of learning and language. A task-based syllabus, then, takes the form of a sequence of integrated tasks which involve speaking and which reflect the situations that learners are likely to meet in real circumstances.

Both approaches have their advantages and drawbacks. The task-based approach has been criticized for giving priority to the process of using language rather than focusing on the language that learners actually produce. The genre-based approach has been considered inadequate as it relies too heavily on imitating models and this is not necessarily the way in which people communicate in real life. It seems, however, that more advanced learners may benefit more from a genre-based framework since it emphasizes the importance of social context, purpose, register and interlocutors' expectations, that is the components of a communicative situation which are seldom covered or analyzed in classrooms at lower levels of language proficiency.

It must be stressed that all oral discourse stems from a communicative intention, that is the speaker has a defined aim which he or she wants to achieve in a particular communicative situation. This situation may require creative thinking and producing a highly personal individualized utterance or relying on automatic reactions in accordance with established social and cultural norms. Yet, in order to implement a communicative goal, a speaker must enable the interlocutor to understand, interpret and evaluate the information being passed. Seen from such a perspective, speaking seems a very complex activity which combines the processes of intending, planning, constructing and monitoring. Additionally, these operations have to be executed in fractions of seconds according to the demands of communicative fluency (Dakowska 2005: 233).

In the light of the above assumptions it may be claimed that ongoing language performance is an extremely significant element in the process of developing speaking skills. In other words, it seems obvious that in order to learn to speak or develop this ability, learners have to speak. As Skehan (1998) claims, a comprehension-based approach is not sufficient on its own, 
and relying on listening tasks as the only source of language input does not guarantee success in language learning. He underlines the importance of output, that is the actual practice of interactive speaking, and identifies the roles it may play in interlanguage development (Skehan 1998: 16-19):

- to generate better input - speaking is used as a signaling device to obtain better input, it enables the negotiation for meaning in the form of clarification requests and comprehension or confirmation checks;

- to force syntactic processing - being aware that they have to speak makes learners more attentive to syntax while listening, as a result listening tasks become more effective for interlanguage development;

- to test hypotheses - it should not be assumed that the learner will individually receive relevant information for the specific needs of his or her interlanguage at the right moment, by speaking the learner controls the present state of his interlanguage, tests hypotheses, takes risks and looks for relevant feedback;

- to develop automaticity - to become effective as a speaker, the learner needs to achieve a degree of ease and a natural level of speed and rhythm, frequent speaking practice is the only way of acquiring such fluency;

- to develop discourse skills - speaking practice cannot focus only on "short turns" but it should also give opportunities for taking part in extended discourse, this allows for developing discourse management and turn-taking skills, which underlie the negotiation of meaning in ongoing communication;

- to develop a personal voice - learners who rely exclusively on what others say are not likely to develop a personal manner of speaking, they are dependent on the meanings they are exposed to and cannot steer conversations, each learner should learn how to meaningfully influence ongoing discourse and find ways of individual expression.

The above approach suggests that frequent and well-planned speaking practice has a great impact on learners' interlanguage development. However, the question of whether it is a sufficient and efficient condition for language learning still remains open for theoretical and practical consideration (Skehan 1998).

\section{PATTERNS OF INTERACTION IN FOREIGN LANGUAGE CLASSROOMS}

In every foreign language classroom, language functions as the medium through which teachers teach and students demonstrate what they have learned (Johnson 1995). Teachers use the target language to control both the 
content and the structure of classroom interactions, learners try to respond to their teachers' use of language. However, the overall picture of classroom communication depends rather on the types of relationships between teachers and learners, and the actual patterns of communication established and maintained during regular lessons. Interestingly, these patterns are hardly ever permanent, but they tend to be reconstructed and modified according to the requirements of the ongoing learning process. This flexible nature of classroom discourse creates the specific dynamics of classroom communication which, in spite of many similarities, are always unique and unpredictable.

In an attempt at constructing an integrated view of communication in second language classrooms, Johnson (1995: 9) presents a framework which may be used for analyzing and describing classroom interaction. The most essential elements of the framework include:

- forms of teachers' control of classroom communication - shaped mostly by their professional and practical knowledge;

- students' perceptions of these patterns - norms and expectations based on their previous learning experience, including preconceived notions of "appropriate" classroom communication;

- students' use of the target language;

- the extent to which the existing patterns of communication create opportunities for students to use the target language for learning.

Analysis of the above elements may prove particularly useful in teaching speaking at advanced level as it allows for the adequate tailoring of the language of instruction and introducing more elements of natural social discourse in a given learning context.

There are two basic types of interaction which may be observed in second and foreign language classrooms: teacher-student and studentstudent interaction. The most traditional version of teacher-student interaction is illustrated by the so-called IRE model (teacher initiation, student response, teacher's evaluation of that response). However, the extent of a teacher's control over classroom communication may vary, connected with the pedagogical purpose of the language course or lesson. The teacher usually relies on a variety of interactive questioning strategies but in less-tightly controlled classes modifications in the IRE model are often observed and learners can take on some part of this sequence. When learners take on all of them (initiation, response, evaluation), the sequence is abandoned altogether and the pattern changes into student-student interaction.

In general, student-student interaction is the dominant pattern of communication in learner-centred classrooms, since it expands student talking time and fosters student use of language for learning, as opposed to only demonstrating what they have learnt. Working in groups on cooperative 
learning tasks produces many constructive student-student interactions which, in turn, enhance learners' educational achievement, aspirations, motivation, self-esteem, positive attitudes to learning (Webb 1982) and helps develop social skills. Yet collaborative learning and speaking tasks may also generate conflicts which are less likely to occur in teacher-centred classes, where teacher-student interaction usually dominates. It must be stressed, nevertheless, that a properly managed cognitive conflict in a group of learners can be constructive as students are exposed to contradictory viewpoints and they have to reorganize their prior ideas and understandings (Cazden 1988). The amount of control that the teacher exerts over student-student interaction may obviously vary but in the situation of cognitive conflict this control should aim at establishing an appropriate climate for negotiation. Thus, the atmosphere in the classroom should be rather cooperative than competitive and students' feelings should be dealt with as well as their differing perspectives (Johnson 1995).

It may be claimed that the student-student interaction practiced in different types of cooperative learning activities is particularly well-suited for higher level students. Advanced and more mature learners are able to use the target language both as a means (while implementing the task in a group) and as an end (producing particular discourse pattern as an outcome of a task). They may also use it for different social purposes according to the demands of current circumstances in the classroom. In other words, the fact that they have already learned a lot, allows them to practice even more extensively and take advantage of every opportunity to communicate in the target language without switching to the mother tongue.

To sum up, student-student interaction, in contrast to teacher-student discourse, ensures optimal conditions for target language learning and use as it opens a space for both meaning-focused and form-focused language practice, enables learners to initiate interaction, control the topic and, last but not least, challenges students to operate beyond their current level of language proficiency by participation in the negotiation of meaning and performing different language functions (Johnson 1995: 100).

\section{SPEAKING ACTIVITIES AT ADVANCED LEVEL}

According to Thornbury (2007: 40), the process of developing speaking skills consists of three stages:

- awareness - learners are made aware of features of target language knowledge, 
- appropriation - these features are integrated into their existing knowledge-base,

- autonomy - learners develop the capacity to mobilize these features under real-time conditions without assistance.

It seems that at the advanced level of foreign language proficiency students and teachers' efforts should be focused on the stage of appropriation and its effective movement towards autonomy in target language use. For that purpose they need a range of speaking tasks that encourage a considerable degree of independence by relying on extensive oral practice (treated as a source of meaningful input and feedback) mainly in the form of studentstudent interactions. The speaking activities presented below take into account the above assumptions.

Conversations in foreign language classrooms are considered to be not the result of language learning but rather the context in which learning actually occurs (Thornbury 2007). On the other hand, it is not easy to incorporate meaningful conversational interactions into a planned lesson as casual conversation is, by its very nature, spontaneous and unstructured. It becomes easier when conversation activities are based on a set of selected themes which are previously negotiated with learners. Useful conversational routines (opening and closing formulas, interrupting, asking for clarification) and helpful communication strategies (paraphrasing and reformulating, using vague language and hesitation fillers) should be taught and practiced beforehand to give students the appropriate devices for successful communication but elements of personalization should be given an equally important status. Conversation activities may proceed from more controlled ones, in which the language is limited by instructions, through awareness activities which make use of audiovisual materials, fluency practice, to feedback sessions during which students analyse their own interactions (Nolasco and Arthur 1987).

Interviews are demanding tasks in the sense that they require from the interviewer some preparation in the form of research, the selection of relevant questions and the prior analysis of native speaker interviews so as to properly evaluate both the questions and the elicited information (Dakowska 2005: 245).

A class survey is a version of a collaborative interview which, if properly carried out, may engage a large group of students in a communicative taskbased activity. Learners prepare a set of survey-type questions connected with a particular topic and they mill around in the classroom, asking the questions and noting the answers. Next, they return to their original groups to analyse the findings which are later reported to the class by a group spokesperson. Finally, the class decides whether the original claim put forward by the group is justified or not (Thornbury 2007: 83). 
Discussion is another popular and useful form of classroom interaction. However, it must be stressed that the actual potential of this activity for developing an individual learner's speaking ability can be implemented only under certain conditions (Dakowska 2005: 245), particularly that:

- the topic is controversial enough to open different perspectives and interpretations,

- learners participate in the choice of the topic and are given enough communicative autonomy to be able to express their personal opinions and ideas,

- students are interested in the topic and their general knowledge is sufficient enough to discuss it (this may require appropriate preparation studying relevant sources and processing the teacher's or peers' input),

- discussion is planned as a complex activity which combines working in pairs or groups and open-class or panel forms of interaction.

A more formal version of discussion is referred to as debate. It involves discussing a topic from two opposing points of view which are earlier ascribed to members of the debating teams (Dakowska 2005: 246). Additionally, new points and arguments may emerge during the discussion. It is important that the arguments are logical and well-balanced and that they are presented in accordance with the social and cultural norms of the target language community.

Academic presentations (Thornbury 2007: 94) are particularly useful for learners who study language for academic purposes and need practice in giving presentations or conference papers. This activity should be preceded by discussing the formal features of the genre and analyzing the specific language patterns typical of each stage of an academic presentation. Watching model or authentic presentations before students actually start preparing their own speeches should be treated as an important part of the activity, as well as discussing the effectiveness of individual presentations (reactions of the audience, delivery style, time - management) afterwards.

Other activities that advanced students may benefit from include: storytelling, jokes and anecdotes which are common ingredients of causal conversations and drama, role-play and simulation activities (Thornbury 2007). They greatly expand the scope of registers and social roles that learners may encounter in the classroom (for example, by introducing simulated interactions with total strangers or face-threatening speech acts). The perception and reception of such tasks, however, may by different in different students and they depend to some extent on the personality of the individual learner.

To conclude, it must be remembered that each speaking task needs to be productive, purposeful, interactive, challenging, safe and authentic (Thornbury 2007: 90) if it is intended to ensure optimal conditions for effective and autonomous language use. 


\section{PROBLEMS OF EVALUATION}

Testing the oral proficiency of foreign language students is a complex task which may cause considerable problems at any stage of the process. The difficulties concern not only the choice of the appropriate elicitation technique and form of assessment, but they may also emerge while designing or administering the test. Practitioners and researchers are divided in their opinions as to the validity of oral testing and put forward arguments for and against it. The most common arguments in favour of testing oral fluency are as follows (Ur 1995: 134):

- Each general language test should include all aspects and areas of the language, therefore it should include speaking;

- Speaking is generally considered to be the most important language skill, that is why it should take priority in any language test;

- An oral proficiency test at the end of the course will guarantee that teachers and students devote more time to speaking practice during the course (the washback effect), otherwise a tendency to neglect extensive speaking practice or not to give it enough time and effort can be observed;

- There are many students who speak well but write badly, a test based on writing may discriminate such learners and their overall assessment will not reflect their actual skills and abilities.

However, there are also numerous convincing arguments against oral testing (Ur 1995: 134):

- Designing valid and reliable tests that make learners improvise speech in the target language is very difficult,

- Speech is very difficult to assess quickly and objectively, recordings can be made but this form of evaluation is extremely time-consuming and it does not guarantee objectivity;

- There is a problem of finding the right balance between accuracy and fluency testing. It is often not clear what criteria should be selected for assessment of the speaking skill or which should be given priority and why;

- Even a well-balanced selection of a set of criteria does not mean that testers will apply them in an identical manner, consistent and objective assessment may be extremely difficult to reach;

- Oral testing is a very time-consuming procedure, students are tested individually or in pairs in real time, educational institutions have problems with ensuring the adequate amount of time for every student to be tested appropriately. 
The above arguments show that an assessment of learners' speaking skills is a very complicated process which involves taking many binding decisions as early as at the stage of planning the language course. Yet, despite all the difficulties, oral testing procedures constitute an important part of overall student evaluation in most institutional language courses. Testing may in fact be the starting point of the course (placement tests) and usually occurs at the end of it, too (achievement tests). There are also tests administered at various times during the course which are meant to measure student progress. Oral testing is practically implemented by means of the following spoken test types (Thornbury 2007: 126):

- Interviews - learners are interviewed individually or in pairs but the formal nature of such interviews hardly ever allows for testing informal, conversational speaking styles and affects the interviewee's performance (the interviewer is also the assessor).

- Live monologues - students present a talk or presentation on a preselected topic. The interviewer effect is then eliminated but the test provides rather restricted information on the speaker's actual skill as it does not check students' ability to handle a casual conversation.

- Recorded monologues or dialogues - they are less stressful than live performance and give examiners more opportunities to work out consistent and possibly more objective assessment.

- Role-plays - this test format may be particularly reliable if it matches the needs of learners and aims of the language course, however the influence of the interlocutor on the performance of the testee is hard to predict and control.

- Collaborative tasks and discussions - learners act as themselves, but similarly to role-plays, the testee is influenced by the interlocutor or interlocutors, the test enables examiners to assess learners' interactive skills and their ability to express personal views.

Deciding on the particular spoken test format entails choosing the relevant set of assessment criteria. There are two basic types of scoring employed in oral testing. Holistic scoring reflects the overall impression the learner made on examiners and it takes the form of a single score, therefore it is often used in informal testing of individual progress. Analytic scoring is more time-consuming as it involves giving a separate score for different aspects of the learner's performance. As a result it takes longer but offers a more complete, varied and, consequently, more reliable picture of students' skills. For these reasons it is more valuable in terms of the received feedback for higher level students. Learners at the advanced level of language proficiency are more likely to benefit from detailed descriptions of their speaking skills than from a single score which depicts their ability to 
communicate in general. The criteria used for any type of scoring usually take into account the categories of grammar, vocabulary, discourse management and interactive communication (Thornbury 2007: 127). The specific, more detailed criteria may be defined within each category with respect to the aims and character of the general evaluation procedure and the chosen spoken test format.

\section{REFERENCES}

Cazden, C.B., 1988. Classroom discourse: The language of teaching and learning. Portsmouth, NH: Heinemann.

Dakowska, M., 2005. Teaching English as a Foreign Language. A Guide for Professionals. Warszawa: Wydawnictwo Naukowe PWN.

Johnson, K.E., 1995. Understanding Communication in Second Language Classrooms. Cambridge: Cambridge University Press.

Nolasco, R., Arthur, L., 1987. Conversation. Oxford: Oxford University Press.

Skehan, P., 1998. A Cognitive Approach to Language Learning. Oxford: Oxford University Press.

Thornbury, S., 2007. How to Teach Speaking. Harlow: Pearson Education Limited.

Ur, P., 1995. A Course in Language Teaching. Practice and Theory. Cambridge: Cambridge University Press.

Webb, N.M., 1982. Student interaction and learning in small groups. In: Review of Educational Research 52 (3), 421-445. 